\title{
Utilization of Global Climate Models (GCMs) to Study Precipitation Extremes in Pakistan
}

\author{
Faisal Baig ${ }^{1}$, Serin Darwish ${ }^{1}$, Qasim Khan ${ }^{1, *}$ and Tahir Mahmood ${ }^{2}$ \\ ${ }^{1}$ Civil \& Environmental Engineering Department, United Arab Emirates University, P.O. Box 15551 Al Ain, \\ UAE; 201990038@uaeu.ac.ae (F.B.); 201150153@uaeu.ac.ae (S.D.) \\ ${ }^{2}$ Department of Agricultural Engineering, Bahauddin Zakariya University, Multan, Pakistan; \\ faisalbaig@bzu.edu.pk (T.M) \\ * Correspondance : 201670249@uaeu.ac.ae
}

\begin{abstract}
Global Climate Model (GCM) downscaling projections of climate is important for future impact of climate change. The impact of climate change on the precipitation is studied using modeling, and observations. The rainfall trend was examined across Pakistan using Global Climate Model (GCM) data from period of 1991 to 2012. Downscaling was done on the basis of ascertained relationships between historical observed precipitation records from 36 stations of Pakistan Meteorological Department (PMD). Mann-Kendall test and Taylor Diagrams were used to analyze the data. All of the selected precipitation products were validated at monthly, seasonal and annual time scales utilizing PMD data. The outcomes illustrated that: (1) the precipitation estimates from MIROC, ECHAM and CanESM products correlated well with the referenced PMD observations at monthly time scale. (2) Compared to the MIROC and CanESM, the precipitation estimates from ECHAM were more consistent in all seasons mainly in the winter season with lowest relative bias (2.61\%) and highest Correlation Coefficient (0.92); (3) ECHAM showed an apparent dominance over MIROC and CanESM products in order to detain spatial distribution of precipitation over Pakistan. The results exposed a declining trend $(-1.18 \mathrm{~mm} /$ decade) over southern part of the country, while northern area showed growing trends. The diminishing trend may be featured to the existence of drought period for next few years in various part of country. The results also indicate spatial and temporal change in precipitation.
\end{abstract}

Keywords: global climate model (GCM); precipitation; climate change; hydrological modeling

\section{Introduction}

Climate models around the globe have provided detailed, organized, accurate and distributed sets of 20th and 21st century climate change experiments. But it is in general realized through nonstationarity in temperature and precipitation with distinct trends in extreme precipitation as one of the key concerns. Environmental hydrology, cropping intensity, vegetation patterns, wildlife ecology, have been influenced by precipitation. These related applications required precise and reliable precipitation data on the basis of well spatial and temporal resolutions. Furthermore, weather prediction and prediction of water associated natural threats (floods, droughts and landslides) require exact precipitation estimations. Lots of casualties happened and lots of people were affected by cruel flooding whose probability has augmented as a partial result of anthropogenic climate changes.

It is imperative to consider the effects of climate change to outline alleviation and variation events. Climate change contributes into long term variations in climate which includes temperature rise, high $\mathrm{CO}_{2}$ and irregular distribution of rainfall quantity [1].

Previous decades showed that there occurred frequency increase, enlarge duration and degree of extreme events which seems to be aggravate in future with an augment in anthropogenic activities (IPCC). Many countries are more sensitive for this pattern. Focusing on Pakistan, which is mostly hit hard by the heat waves and intense flooding [2-4]. 
There is need to point out the information on future climate impacts which lead to timely managed policies. These strategies of projection give the basic relevant detail to policy makers. This can be carried out by climate models. But the main focus is to efficiently project the current and future climate conditions because of huge qualms arising throughout the proper authentication and justification processes [5].

Many researchers have exploited the Global Climate Models outputs during the last many decades. GCM is deemed as the main consistent tool to simulate climate's time series [6]. GCMs are assumed as the most advanced models to forecast the changes of the earth's climate. These are basically computer oriented models that pursue the laws of thermodynamics and physics. These models basically work on mathematical equations to anticipate the atmosphere. It is widely recognized that the GCMs are able to symbolize the physical methods of the global climate. Numerous GCMs results are capable to utilize by the hydrological projections to estimate the effects of climate changes on the environmental reactions worldwide.

So, there is need to study the climate changes with possible future precipitations and its changing with passage of time [5]. GCMs are considered as best tools that are present currently which use climate replications to generate climatic conditions for past and future time. They show an essential function in propagating future protuberances of climate change by using various emission circumstances [7].

Tank et al. [8] explained there is always need to establish a comparison between climate models to ensure the effectiveness for policy makers regarding their accuracy. Main reason for comparison is that no single model predicts all the climate features well. $[9,10]$ reveals the flaws of GCMs that these are unable to fetching information for hilly areas where topography is uneven due to their coarse horizontal resolutions at finer local. Furthermore one GCM may perform well for one climatologically process and less for other.

This study intends to determine precipitation extremes based on General Circulation Models in Pakistan. The main objectives of this study are:

- Predicting the trends of precipitation for future scenarios using outputs of GCMs

- Examine the precipitation extremes based on General Circulation Models in Pakistan.

\section{Materials and Methods}

\subsection{Study Area and Data used}

Pakistan is situated among $24-37^{\circ} \mathrm{N}$ and $62-75^{\circ} \mathrm{E}$ from south Asia western part (Figure 1). It has total area of $881,913 \mathrm{~km}^{2}$. Pakistan's climate have primarily two raining seasons (1) summer monsoon which consists on (July, August \& September) and (2) winter season (December, January, February \& March) having area weighted annual rainfall of $238 \mathrm{~mm}$. The composition for the contribution of rainfall for summer is $137.5 \mathrm{~mm} \mathrm{(57 \% )} \mathrm{\&} \mathrm{for} \mathrm{winter} \mathrm{is} 74.9 \mathrm{~mm}(30 \%)$. Thunderstorms contributed the rest of rainfall which is $25.6 \mathrm{~mm}(13 \%)$.

The observed monthly rainfall data from 36 gauging stations was utilized in the study which was distributed evenly for the period of 22 years over the Pakistan region. The data was obtained from Pakistan Meteorological Department (PMD) climate data processing centre (CDPC).

Two types of datasets have been considered for this research (1) observed (2) climate model's simulated data. Observed/Historical data were gained from (PMD) on monthly frequency for rainfall for various sites of Pakistan. Model's simulated data were collected from National Institute of Environmental Studies MIROC3.2 (medres), Canadian Earth System Model (CanESM), Max Planck Institute for Meteorology (ECHAM). We used baseline time period data for 1991-2012 for both observed and simulated data. 


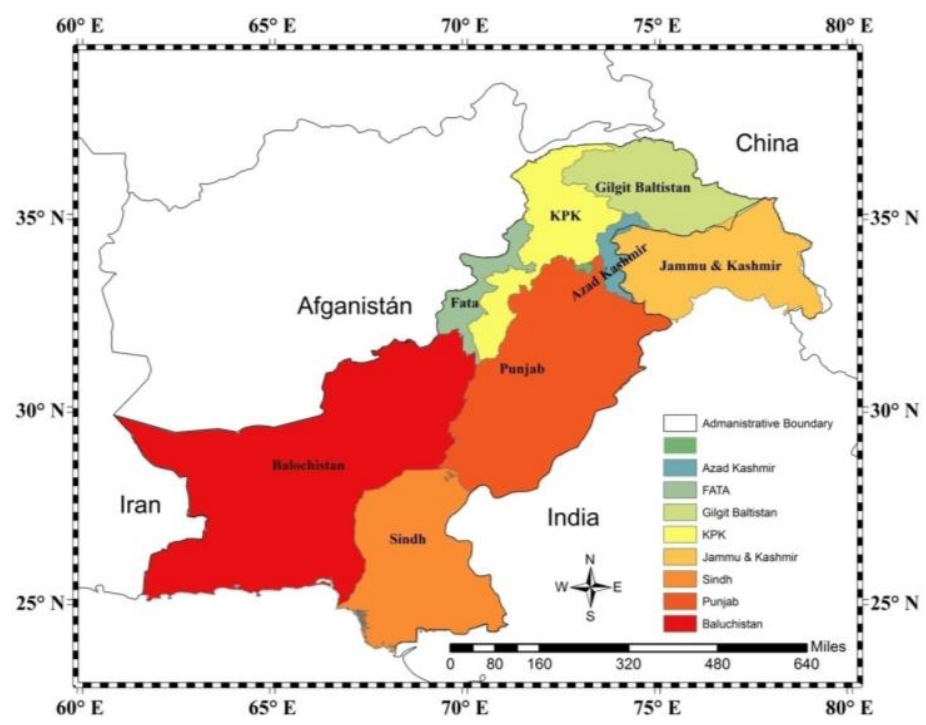

Figure 1. Map of the study area Pakistan located in south Asia.

\subsection{Methodology}

The basic methodology focused on evaluation of climate models. We estimate these models output due to different qualms before using for additional investigation. For this purpose, observational and historical model's simulated data is needed for the precipitation and for the same time stage. Observational data is obtained from PMD stations and the data obtained from three GCMs namely MIROC, ECHAM, CanESM for the period 1991-2012. Since the data was raw and need to be corrected, so downscaling is done by bias correction. This method is basically an algorithm that is accomplished by adding the inconsistency of past climates to future projections. This can be carried out by two-step approach, which generates a delta or delta factor firstly and then alters an observed sequence by the delta or delta factor. Delta factors are developed by dividing future projected values by historic modeled values for precipitation. Precipitation delta factors are then multiplied by a past observed time series of precipitation. Delta method for bias correction is calculated by Equation (1);

$$
P_{\text {pre }}=P_{G C M} \times \frac{\mu\left(P_{o b s}\right)}{\mu\left(P_{G C M}\right)}
$$

where $P_{G C M}$ is for GCM's precipitation data and $P_{o b s}$ is for observed precipitation data while $\mu$ is for the mean of data for this period.

\subsection{Mann-Kendell Trend Detection Test}

The trends in precipitation time series data can be identified by Mann Kendall (MK). The significance of trend is measured by standardized $Z$ value which has calculated by Mann-Kendall test. Result of this test statistic is used to check the null hypothesis, H0. Hypothesis (H0) is accepted for and assumed as no trend if the premeditated value of $Z$ lies between $-Z 1-\alpha / 2$ and Z1- $\alpha / 2$. The occurrence of linear trend or normal distribution is not a necessary condition for measurements. The positive point for this test is that this test can be applied if the values are less than one or have some missing values. There would be negatively effect on the performance of test for such events. The trend analysis by mean of MK test is carried out by many researchers for metrological data such as temperature and precipitation to fulfill this objective [11-14].

\subsection{Statistical Analysis}

Generally exploited statistical indicator metrics used for this study are Nash Sutcliffe efficiency (NSE), Root Mean Square Error (RMSE), Standard Deviation (SD), coefficient of determination $\left(R^{2}\right)$, Bias, relative Bias (rBias) and Pearson Correlation Coefficient (CC) which have employed on monthly, seasonally and annually. Linear correlation between the PMD ground based data and the GCM based 
data have estimated by the dimensionless statistical tool (CC). Above mentioned statistical formulas can be calculated by following Equations (2)-(6):

$$
\begin{gathered}
R=\frac{\sum_{i=1}^{N}\left(X_{o b s, i}-X^{-}{ }_{o b s}\right)\left(X_{\text {sim }, i}-X^{-}{ }_{\text {sim }, i}\right)}{\sqrt{\sum_{i=1}^{N}\left(X_{o b s, i}-X^{-}{ }_{o b s}\right)^{2} \sum_{i=1}^{N}\left(X_{s i m, i}-X^{-}{ }_{s i m}\right)^{2}}} \\
N S E=1-\frac{\sum_{i=1}^{N}\left(X_{\text {sim }, i}-X_{o b s, i}\right)^{2}}{\sum_{i=1}^{N}\left(X_{o b s, i}-X^{-}{ }_{o b s}\right)^{2}} \\
M B=\frac{1}{N} \sum_{i=1}^{N}\left(X_{\text {sim }, i}-X_{o b s, i}\right) \\
r B I A S=\frac{\sum_{i=1}^{N}\left(X_{\text {sim }}-X_{o b s}\right)}{\sum_{i=1}^{N} X_{o b s}} \times 100 \\
R M S E=\left[\frac{1}{N} \sum_{i=1}^{N}\left(X_{\text {sim }, i}-X_{o b s, i}\right)^{2}\right]^{\frac{1}{2}}
\end{gathered}
$$

where gauge observation represented by $X_{o b s}$, GCM data denoted by $X_{s i m}, X_{o b s, i}$ is the $i_{t h}$ observed precipitation, $X_{\text {sim }, i}$ is the $i_{t h}$ simulated Raw or downscaled GCM precipitation and total number of observation expressed by $N$.

\section{Results}

\subsection{Observation Trends}

Monthly PMD data across the stations indicate variance in precipitation pattern. Seasonal precipitation increased per decade for northern areas and decrease for southern areas which is similar to other studies for this area [12-15]. Figure 2 and Figure 3 present accuracy of the rainfall data obtained from all 36 PMD stations and GCM's output precipitation data. Graph consequences explain the comparison of efficiencies of CanEsm and MIROC products which have the maximum total annual rainfall for CanEsm and lowest total annual precipitation for MIROC at most of the PMD stations. The ECHAM model summarized an augment in the rainfall data for the period from 1991 to 2012 at $50 \%$ of the stations. The normal distribution for the models data sets were much closed to the observation data (i.e., PMD).

NSE and Correlation is drawing on to inspect the trend of the modeled precipitation data with the observed PMD data. Below graphs represent succinct review of an assessment of the in situ and modeled datasets in sense of correlation, Standard Deviation SD and NSE. The correlation coefficient value is up to 0.92 . MIROC showed the best harmony with the observed data (PMD). In distinction, ECHAM was initiated to being fewer constant as compared to PMD observed data. 


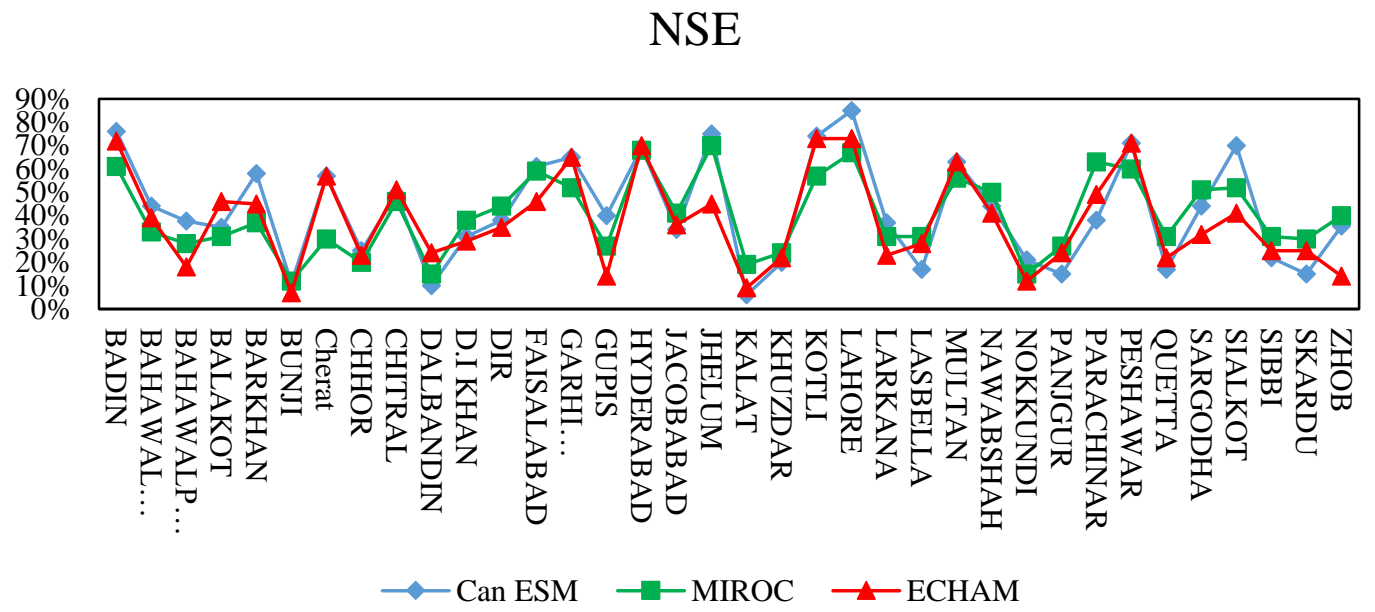

Figure 2. Efficiencies of 3 GCMs output computed with PMD precipitation data.

\section{Correlation}
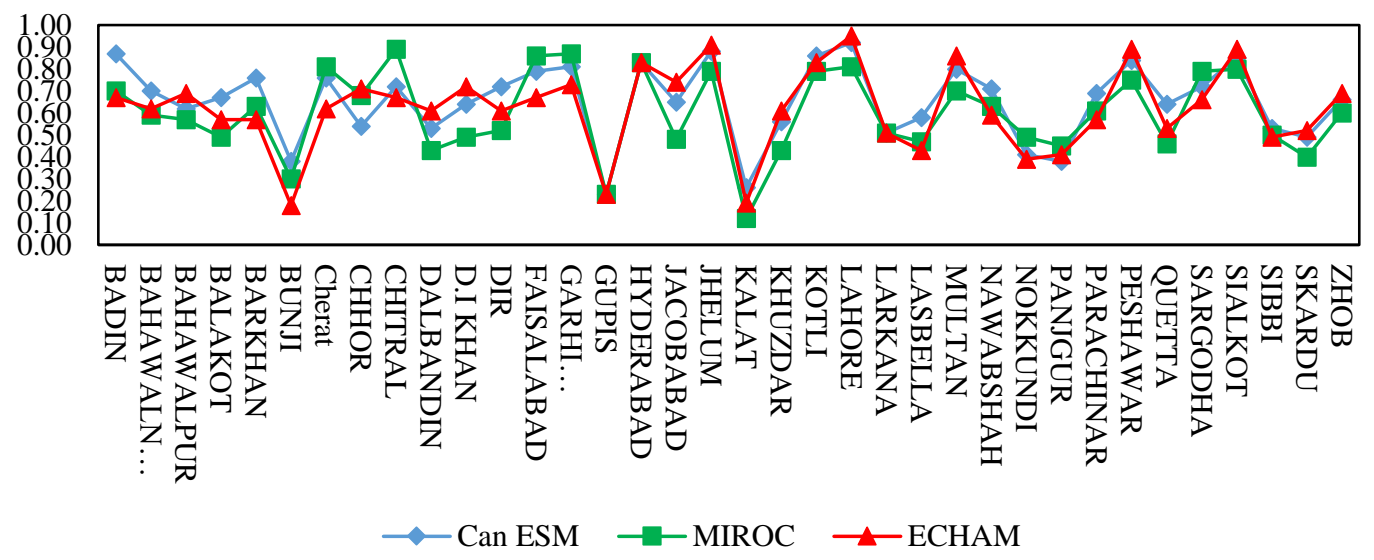

Figure 3. Correlation for GCMs output computed with PMD Precipitation data.

Table 1 shows the Bias values calculated for all the GCM outputs for all the gauging stations. It is evident that the highest positive bias values for all the GCMs were found for Larkana station while the lowest bias value was found for Dalbandin station. Apparently, all the bias values have positive values which depicts the over estimation of the precipitation data by all the three GCMs.

Table 1. Bias values calculated from all GCMs outputs.

\begin{tabular}{cccccccc}
\hline Stations & MIROC & ECHAM & CanESM & Stations & MIROC & ECHAM & CanESM \\
\hline Badin & 0.59 & 0.64 & 0.48 & Kalat & 3.04 & 2.89 & 3.11 \\
BWNGR & 1.73 & 1.68 & 1.42 & Khuzdar & 0.63 & 0.56 & 0.86 \\
BWP & 1.23 & 1.18 & 0.92 & Kotli & 1.16 & 0.45 & 0.12 \\
Balakot & 0.31 & 0.37 & 0.20 & Lahore & 1.24 & 0.53 & 0.20 \\
Barkhan & 0.47 & 0.42 & 0.16 & Larkana & 4.66 & 5.08 & 5.89 \\
Bunji & 0.45 & 0.50 & 0.34 & Lasbella & 1.73 & 2.25 & 2.49 \\
Cheerat & 2.18 & 2.49 & 2.81 & Multan & 1.42 & 1.26 & 0.82 \\
Chhor & 0.15 & 0.30 & 0.04 & Nawabshah & 0.72 & 0.98 & 0.95 \\
Chitral & 0.36 & 0.49 & 0.20 & Nokkundi & 0.85 & 0.69 & 0.25 \\
Dalbandin & 0.20 & 0.32 & 0.03 & Panjgur & 0.84 & 0.68 & 0.24
\end{tabular}




\begin{tabular}{cccccccc} 
DIK & 1.23 & 1.56 & 1.46 & Parachinar & 1.04 & 1.04 & 0.75 \\
DIR & 0.16 & 0.47 & 0.36 & Peshawar & 1.08 & 0.92 & 0.48 \\
Faisalabad & 0.50 & 0.83 & 0.73 & Quetta & 1.10 & 0.99 & 0.50 \\
Garhi Dupatta & 1.26 & 0.95 & 0.22 & Sargodha & 1.95 & 2.60 & 2.88 \\
Gupis & 0.75 & 0.88 & 0.59 & Sialkot & 0.79 & 0.63 & 0.10 \\
Hyderabad & 1.00 & 1.32 & 1.23 & Sibbi & 0.26 & 0.34 & 0.05 \\
Jacobabad & 0.72 & 0.45 & 0.56 & Skardu & 0.16 & 0.47 & 0.39 \\
Jhelum & 1.26 & 0.55 & 0.22 & Zhob & 0.51 & 0.55 & 0.20 \\
\hline
\end{tabular}

\subsection{Temporal and Spatial Rainfall Distribution}

Figure 4 shows the deviations in the yearly rainfall time chain at 36 in situ stations. The transform in the yearly rainfall is not in accordance at diverse meteorological stations. The study area is prejudiced by dissimilar climatic systems such as monsoon affects, westerly disturbances and orographic distinctions of the Tibetan Plateau. These different factors are making this region a complex region and are showing these inconsistencies at different PMD stations.
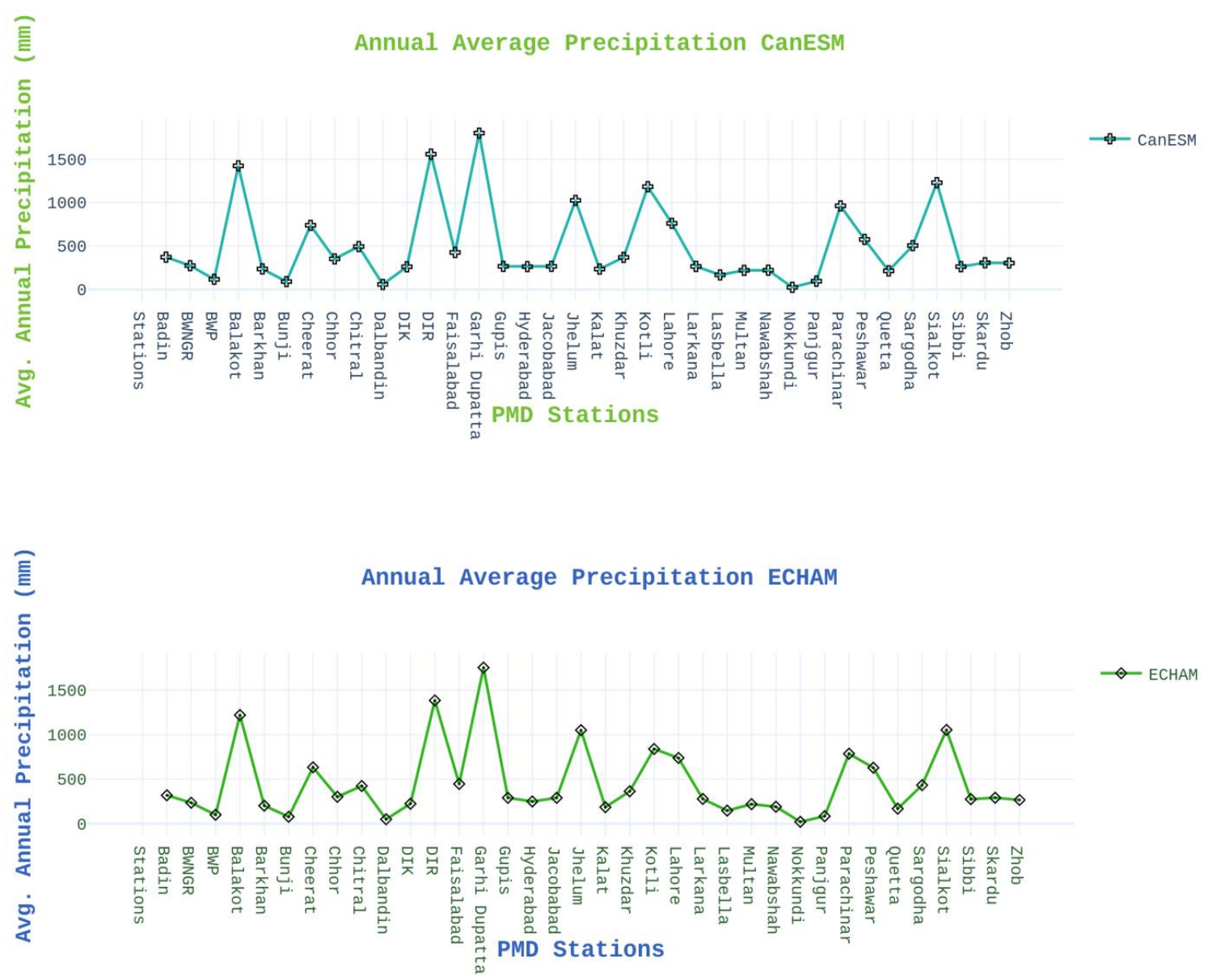


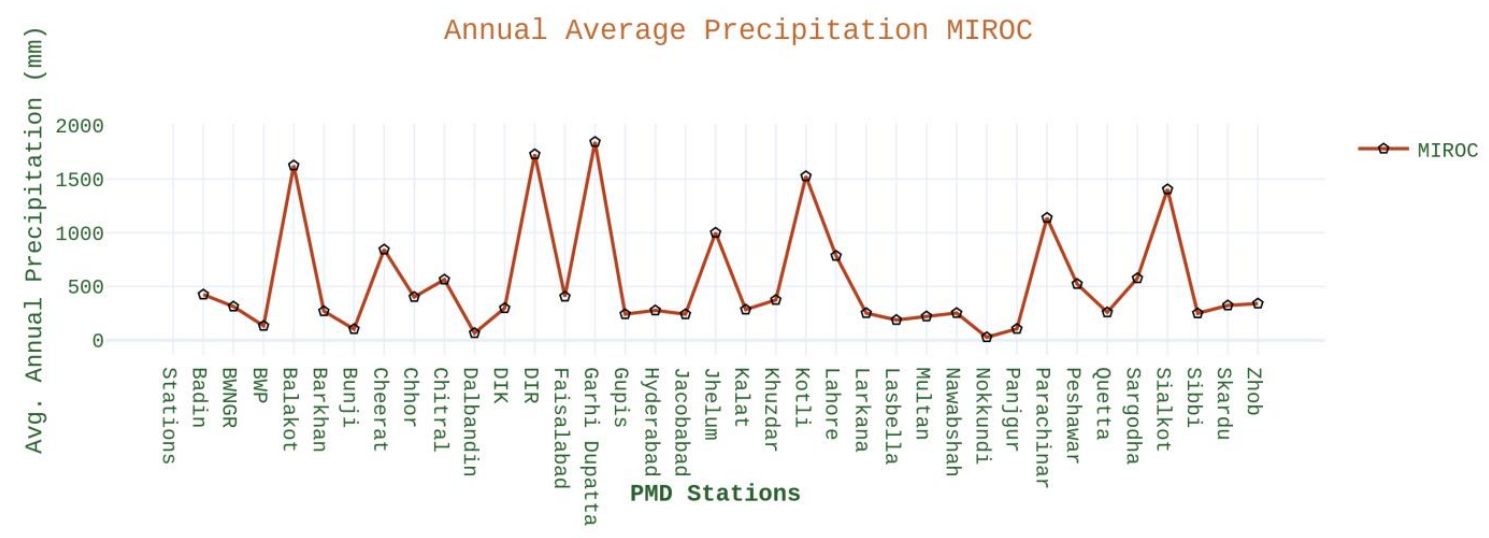

Figure 4. Average annual precipitation ( $\mathrm{mm}$ ) at PMD stations over Pakistan.

\subsection{Seasonal Trend Analysis}

PMD station's seasonal precipitation trends are inspected by Mann-Kendall test and Sen's slope estimator test. Results for MK test are accessible in Table 2. A trend analysis [12-14,15] of PMD station's and Modeled precipitation data at yearly scale as well as at seasonal scale was done to analyse the tendency in the precipitation. Their outcomes summarized for MIROC model showed that 9 out of 36 stations have negative trend while the residual stations showed a non significant positive trend. The trend analysis for ECHAM Modeled precipitation data products indicated that the there is non-significant negative trend at 8 out of 36 stations. CanESM model output data showed a non-significant negative trend at 10 out of 36 stations. Collectively, the ECHAM model showed satisfactory performance with PMD station as compared to the MIROC and CanESM for estimation of trend analysis.

Table 2. Mann Kendall's Z values for PMD stations from GCMs output data for 2020-2099.

\begin{tabular}{cccccccc}
\hline Stations & MIROC & ECHAM & CanESM & Stations & MIROC & ECHAM & CanESM \\
\hline Badin & -1.24 & 1.12 & -1.42 & Kalat & 1.51 & 1.29 & 1.46 \\
BWNGR & 0.60 & 1.98 & -0.35 & Khuzdar & 0.58 & 0.93 & 0.76 \\
BWP & 0.45 & 0.34 & 0.82 & Kotli & 2.53 & 2.89 & 2.11 \\
Balakot & 2.07 & 2.77 & 1.32 & Lahore & 1.32 & 1.95 & 1.03 \\
Barkhan & -0.10 & 0.50 & -1.42 & Larkana & -0.46 & -0.68 & -0.82 \\
Bunji & 1.17 & 1.96 & 1.60 & Lasbella & -0.61 & -0.75 & -0.75 \\
Cheerat & 1.87 & 1.50 & 1.05 & Multan & -0.01 & -0.49 & -0.87 \\
Chhor & -0.06 & -0.62 & -1.51 & Nawabshah & -0.90 & -1.62 & -1.17 \\
Chitral & 1.73 & 2.28 & 1.95 & Nokkundi & 0.46 & -0.18 & 0.80 \\
Dalbandin & 0.90 & 0.90 & 0.90 & Panjgur & 0.24 & 0.82 & 0.53 \\
DIK & 1.06 & 1.94 & 2.44 & Parachinar & 1.91 & 1.99 & 1.51 \\
DIR & 2.03 & 2.03 & 2.03 & Peshawar & 1.95 & 1.85 & 1.67 \\
Faisalabad & 1.42 & 1.99 & 1.88 & Quetta & 1.24 & 1.45 & 1.62 \\
Garhi Dupatta & 2.40 & 2.17 & 2.88 & Sargodha & 1.91 & 1.49 & 1.00 \\
Gupis & 2.19 & 1.90 & 1.52 & Sialkot & 2.01 & 1.95 & 2.70 \\
Hyderabad & -0.87 & -0.93 & -0.99 & Sibbi & 0.86 & 0.96 & 0.82 \\
Jacobabad & -0.25 & -0.48 & -0.79 & Skardu & 2.63 & 2.93 & 2.09 \\
Jhelum & 2.15 & 2.93 & 2.60 & Zhob & 0.96 & 0.92 & 1.25 \\
\hline
\end{tabular}

\section{Conclusion and Recommendation}

This research interrogates the precipitation inconsistency over Pakistan on seasonal and annual scale by using Mann-Kendall (MK), Sen's slope estimator tests and statistical analysis. The results of 
this study displayed noteworthy trends at twenty (20) PMD stations in four seasons. The analysis predicted significant rising trends at five stations in the winter precipitation and rising trend for autumn precipitation time series at three stations. Further study revealed there are significant declining trends at twenty stations for spring precipitation. There are also significant trends at eleven stations for summer precipitation. Six stations out of eleven projected to have rising trend and remaining five showed decreasing trends. There are stations like Chitral, DIR, Garidopatta, Peshawar, Skardu and Gupis which are initiate more responsive to seasonal rainfall variations.

The summary of study is that mostly stations having significant trends are situated in the northeast and northwest part of the study area. The results revealed that there will be a likely exacerbation of flooding in winter and summer seasons in the northern part of study area. The stations having decreasing trends for spring season are situated in the southeast region which are presenting a decline in flooding. The light precipitation also causes a growing trend in the summer season at seven stations; and a diminishing trend in the winter season at twenty stations. The spring season displayed decreasing trend at ten stations. It can be said that winter and summer seasons are more responsive to extreme precipitation values.

There is need to give attention to deal with flooding and droughts like circumstances during these sensitive seasons. There is significant trend on 20 out of 36 stations on annual scale. Twelve out of twenty stations show increasing trends while eight stations show a decreasing trend. Southeast regions are projected to show declining trends and there is increasing trends in southwest and northeast area. The projected diminishing rates of significant trends are $-5.57 \mathrm{~mm} / \mathrm{year}$ and -6.56 $\mathrm{mm} /$ year at two stations. The rising rates of trends diverge from $0.82 \mathrm{~mm} /$ year to $2.64 \mathrm{~mm} / \mathrm{year}$. The conclusion of this research presents an approach into future improvement projects. At this instance this research work can present precious information and a valuable examination to shore up the engineers and practitioners to execute the structures to be constructed to deal with the floods and droughts when looking at existing climatic events.

Acknowledgments: We would like to appreciate efforts of Ahmed Agiel for guiding and teaching us the fundamentals of conducting research in the course MECH710 Research Methodologies at United Arab Emirates University. Thanks to the Pakistan Meterological Department, Islamabad for providing us the historical ground values of precipitation.

Author Contributions: F.B. and T.M. conceived and designed the study; F.B. and T.M. performed the data acquisition; S.D. and Q.K. analyzed the data; F.B., S.D. and Q.K. contributed analysis tools; F.B., S.D., Q.K. and T.M. wrote the paper.

Conflicts of Interest: The authors declare not conflict of interest.

\section{References}

1. Ahmed, Kamal, Shamsuddin Shahid, and Nadeem Nawaz. 2018. "Impacts of Climate Variability and Change on Seasonal Drought Characteristics of Pakistan." Atmospheric Research 214(July): 364-74. https://doi.org/10.1016/j.atmosres.2018.08.020.

2. Ahmad, B, G Rasul, W Iqbal, and S A A Bukhari. 2014. "Regional Comparison between Global Circulation Model GCM20 and Regional Climate Model PRECIS." Pakistan Journal of Meteorology 11(21): 39-51. http://www.pmd.gov.pk/rnd/rndweb/rnd_new/journal/vol11_issue21_files/4.pdf.

3. Ahmed, Kamal et al. 2019. "Climate Change Uncertainties in Seasonal Drought Severity-Area-Frequency Curves: Case of Arid Region of Pakistan." Journal of Hydrology 570(February 2017): 473-85. https://doi.org/10.1016/j.jhydrol.2019.01.019.

4. Anjum, Muhammad Naveed et al. 2018. "Performance Evaluation of Latest Integrated Multi-Satellite Retrievals for Global Precipitation Measurement (IMERG) over the Northern Highlands of Pakistan." Atmospheric Research 205(October 2017): 134-46.

5. Hijmans, Robert J. et al. 2005. "Very High Resolution Interpolated Climate Surfaces for Global Land Areas.” International Journal of Climatology 25(15): 1965-78.

6. Islam, Siraj Ul, Nadia Rehman, and Muhammad Munir Sheikh. 2009. "Future Change in the Frequency of Warm and Cold Spells over Pakistan Simulated by the PRECIS Regional Climate Model." Climatic Change 94(1-2): 35-45. 
7. Iqbal, Muhammad Farooq, and H. Athar. 2018. “Validation of Satellite Based Precipitation over Diverse Topography of Pakistan." Atmospheric Research 201(August 2017): 247-60. https://doi.org/10.1016/j.atmosres.2017.10.026.

8. Klein Tank, Albert M.G. et al. 2006. “Changes in Daily Temperature and Precipitation Extremes in Central and South Asia." Journal of Geophysical Research Atmospheres 111(16): 1-8.

9. Kripalani, R. H. et al. 2007. "South Asian Summer Monsoon Precipitation Variability: Coupled Climate Model Simulations and Projections under IPCC AR4." Theoretical and Applied Climatology 90(3-4): 13359.

10. Amin, Asad et al. 2017. “Comparison of Future and Base Precipitation Anomalies by SimCLIM Statistical Projection through Ensemble Approach in Pakistan." Atmospheric Research 194(January): 214-25.

11. McSweeney, C. F., R. G. Jones, R. W. Lee, and D. P. Rowell. 2015. “Selecting CMIP5 GCMs for Downscaling over Multiple Regions." Climate Dynamics 44(11-12): 3237-60.

12. Osborn, Timothy J., Craig J. Wallace, Ian C. Harris, and Thomas M. Melvin. 2016. “Pattern Scaling Using ClimGen: Monthly-Resolution Future Climate Scenarios Including Changes in the Variability of Precipitation." Climatic Change 134(3): 353-69.

13. Sanjay, Jayanarayanan et al. 2017. "Downscaled Climate Change Projections for the Hindu Kush Himalayan Region Using CORDEX South Asia Regional Climate Models." Advances in Climate Change Research 8(3): 185-98. https://doi.org/10.1016/j.accre.2017.08.003.

14. Trzaska, S, and E Schnarr. 2014. "A Review of Downscaling Methods for Climate Change Projections." Review (September): 1-42.

15. Ullah, Safi, Qinglong You, Waheed Ullah, and Amjad Ali. 2018. “Observed Changes in Precipitation in China-Pakistan Economic Corridor during 1980-2016.” Atmospheric Research 210(May): 1-14.

(C) 2019 by the authors; licensee MDPI, Basel, Switzerland. This article is an open access article distributed under the terms and conditions of the Creative Commons by Attribution (CC-BY) license (http://creativecommons.org/licenses/by/4.0/). 